\title{
Droplet size distribution measurement of water in kerosene by the buoyancy weighing-bar method
}

\author{
Rondang Tambun*, Piety Sibagariang, Brigitta Alphantaria, and Ahmad Mulia Rambe \\ Department of Chemical Engineering, Universitas Sumatera Utara, Padang Bulan, Medan 20155, Indonesia
}

\begin{abstract}
The buoyancy weighing-bar method (BWM) is a method that requires a simple apparatus set up yet produce the high accuracy result in particle size distribution measurement both settling and floating particles. The principle of this experiment that measurement the density change in a suspension due to particle migration is measured by weighing buoyancy against a weighing bar hung in the suspension, and the particle size distribution is calculated using the length of the weighing bar and the time-course change in the apparent mass of the weighing bar. In this study, the BWM was applied to determine the separation time and droplet size distribution for liquid-liquid systems with the different density. The mixture of $99 \%$ of kerosene and 1 $\%$ of water were used as samples. The data obtained of separation time of water-kerosene mixture by the BWM were analyzed by the gas chromatography, and the droplet size distributions were compared to Coulter counter method. Based on the data obtained, the BWM could be used to determine the optimal time of waterkerosene separation. The BWM also could measure the droplet size distribution of water in kerosene and the data obtained were comparable to that measured by Coulter counter method. Hence, the BWM is a novel method in separation time determination of water-kerosene mixture and droplet size distribution measurement of water in kerosene.
\end{abstract}

\section{Introduction}

The buoyancy weighing-bar method (BWM) is a method that requires a simple apparatus set up yet produce the high accuracy result in particle size distribution measurement, for both settling and floating particle. The principle of this method that measurement the density change in a suspension due to particle migration is measured by weighing buoyancy against a weighing bar hung in the suspension, and the particle size distribution (PSD) is calculated using the length of the weighing bar and the time-course change in the apparent mass of the weighing bar. This apparatus consists of an analytical balance with a hook for underfloor weighing, a personal computer, and a weighing bar, which is used to detect the density change of suspension [1-4]. The BWM also could be used to estimate the size distribution measurement of fine particles by using combination with the RosinRammler equation [5]. Obata et al. have reported the measurements of PSD by fluidization in the laminar to turbulent flow region, and one of them can be obtained by a graphical measurement using a fluidization curve [6-8]. The fluidization curve is constructed using the same algorithm as the sedimentation balance method [9].

In this work, the droplet size distribution (DSD) for liquid-liquid systems with the different density would be determined. Some studies have investigated the DSD by using the other methods, such as light scattering method [10], microscope [11], nuclear magnetic resonance [12], etc. These methods could produce highly accurate results within a shorter time, but they require extremely expensive equipment. Hence, a simple and cost effective method to determine the DSD is highly demanded, that is BWM. Beside the DSD, the BWM also could be used to estimate the separation time of liquid-liquid systems with the different density. The principle of BWM in this experiment is analogous to distributions of the settling particles and floating particles. In this method, the initial buoyant mass of the weighing bar W0 depends on the droplets between the top and bottom of the weighing bar in a suspension. The initial density of suspension $\rho_{s 0}$, initial buoyant mass of the weighing bar $\mathrm{W}_{0}$, and initial apparent mass of the weighing bar $\mathrm{G}_{0}$ in a suspension at $\mathrm{t}=0$ are given by the following equations.

$$
\begin{gathered}
\rho_{\mathrm{S} 0}=\rho_{\mathrm{L}}+\frac{C_{0}}{\rho_{\mathrm{P}}}\left(\rho_{\mathrm{P}}-\rho_{\mathrm{L}}\right) \\
W_{0}=V_{\mathrm{B}} \rho_{\mathrm{S} 0} \\
G_{0}=V_{\mathrm{B}} \rho_{\mathrm{B}}-W_{0}=V_{\mathrm{B}}\left(\rho_{\mathrm{B}}-\rho_{\mathrm{S} 0}\right)
\end{gathered}
$$

where $\rho_{\mathrm{L}}$ and $\rho_{\mathrm{P}}$ are the liquid density and droplet density, respectively. $\mathrm{C}_{0}$ is the initial droplet mass

\footnotetext{
* Corresponding author: rondang@usu.ac.id
} 
concentration of suspension, $\rho_{\mathrm{B}}$ is the density of the weighing bar in suspension, and $V_{B}$ is the volume of the weighing bar.

The droplet mass concentration of suspension $\mathrm{C}(\mathrm{t})$ decreases with time because the large droplets settle. The density of suspension $\rho$, buoyant mass of the weighing bar $\mathrm{W}$, and apparent mass of the weighing bar $\mathrm{G}$ in a suspension at time $\mathrm{t}$ are expressed as

$$
\begin{gathered}
1 \\
\rho_{\mathrm{S}}(t)=\rho_{\mathrm{L}}+\frac{C(t)}{\rho_{\mathrm{P}}}\left(\rho_{\mathrm{P}}-\rho_{\mathrm{L}}\right) \\
W(t)=V_{\mathrm{B}} \rho_{\mathrm{S}}(t) \\
G(t)=V_{\mathrm{B}} \rho_{\mathrm{B}}-W(t)=V_{\mathrm{B}}\left(\rho_{\mathrm{B}}-\rho_{\mathrm{S}}(t)\right)
\end{gathered}
$$

The droplet mass concentration of suspension $C(t)$ becomes zero once all the small droplets also settle. The final density of suspension $\rho_{\mathrm{s} \infty}$, final buoyant mass of the weighing bar $W_{\infty}$, and final apparent mass of the weighing bar $G_{\infty}$ in a suspension at $t=\infty$ are given by the following equations.

$$
\begin{gathered}
\rho_{\mathrm{S} \infty}=\rho_{\mathrm{L}} \\
W_{\infty}=V_{\mathrm{B}} \rho_{\mathrm{L}} \\
G_{\infty}=V_{\mathrm{B}} \rho_{\mathrm{B}}-W_{\infty}=V_{\mathrm{B}}\left(\rho_{\mathrm{B}}-\rho_{\mathrm{L}}\right)
\end{gathered}
$$

Equation (10) shows the mass balance of droplets [13].

$$
C_{0}-C(t)=C_{0} \int_{x_{i}}^{x_{\max }} f(x) \mathrm{d} x+C_{0} \int_{x_{\min }}^{x_{i}} \frac{v(x) t}{h} f(x) \mathrm{d} x
$$

The left side in Eq. (10) is the quantity of droplets that move onto the bottom side of the weighing bar. The first term on the right side represents the mass of droplets larger than droplet size $x_{\mathrm{i}}$ among the droplets that move, while the second term on the right side is the mass of droplets smaller than droplets size $x_{\mathrm{i}}$ among the droplets that move. In the sedimentation balance theory [9], the mass frequency function of a given sample droplets is $f(x)$ where $x$ is the Stokes diameter. From Eqs. (2), (5), (8), and (10), Eq. (11) describes the mass balance of particles in a suspension [13].

$$
\begin{aligned}
W_{0}-W(t)= & \left(W_{0}-W_{\infty}\right) \int_{x_{i}}^{x_{\max }} f(x) \mathrm{d} x+ \\
& \left(W_{0}-W_{\infty}\right) \int_{x_{\min }^{i}}^{x_{i}} \frac{v(x) t}{h} f(x) \mathrm{d} x
\end{aligned}
$$

where $v(x)$ is the settling velocity of the droplet and $f(x)$ is the mass frequency of the droplet size $x$. Differentiating Eq. (11) with respect to the time $t$ gives

$$
-\frac{d W}{d t}=\left(W_{0}-W_{\infty}\right) \int_{x_{\min }^{i}}^{x_{i}} \frac{v(x)}{h} f(x) d x
$$

From Eqs. (11) and (12),

$$
W=W_{\mathrm{R}}+\left(\frac{d W}{d t}\right) t
$$

The apparent mass of the weighing bar, which is given by Eq. (6), gradually increases from $G_{0}$ to $G_{\infty}$. The volume and density of the weighing bar are constant values. Differentiating Eq. (6) with respect to time $t$ gives

$$
\frac{d G}{d t}=-\frac{d W}{d t}
$$

Therefore, according to Eqs. (6), (13), and (14),

$$
G=V_{\mathrm{B}} \rho_{\mathrm{B}}-W_{\mathrm{R}}+\left(\frac{d G}{d t}\right) t=G_{\mathrm{R}}+\left(\frac{d G}{d t}\right) t
$$

where $G_{\mathrm{R}}=V_{\mathrm{B}} \rho_{\mathrm{B}}-W_{\mathrm{R}}$. The value of $G_{\mathrm{R}}$ is calculated from the tangent line based on Eq. (15). The cumulative mass oversize is

$$
R=100 \int_{x}^{x_{\max }} f(x) d x=\frac{G_{0}-G_{\mathrm{R}}}{G_{0}-G_{\infty}} \times 100=100-D
$$

where $D$ is the cumulative mass undersize.

Droplets size $x$ is given by Stokes formula,

$$
x=\sqrt{\frac{18 \mu_{\mathrm{L}} v(x)}{g\left(\rho_{\mathrm{L}}-\rho_{\mathrm{P}}\right)}}
$$

The settling velocity of the droplets $v(x)$ is calculated using Eq. (18)

$$
v(x)=\frac{h}{t}
$$

where $h$ is the length of the weighing bar and $t$ is the time lapse. From Eqs. (17), time $t$ is an inverse function of droplet size $x$. The DSD of the suspended droplets is calculated using the droplet size at each time and then plotting the corresponding cumulative mass undersize $D$. According to equations above, this study will try to investigate the DSD of water in kerosene by using BWM.

\section{Materials and Methods}

Figure 1 schematically illustrates this experiment. The weighing-tools was weighing-bar ( $\phi 10.0 \mathrm{~mm}$ x 210.0 mm, submerged length: $200.0 \mathrm{~mm}$ ) which was composed of alumunium (density: $2700 \mathrm{~kg} / \mathrm{m}^{3}$ ). The samples consist of kerosene $\left(\rho=0.810 \mathrm{~g} / \mathrm{cm}^{3}\right)$ and water $\left(\rho=0.99708 \mathrm{~g} / \mathrm{cm}^{3}\right)$ were placed in a $1000 \mathrm{ml}$ of graduated cylinder with the ratio $99 \%$ of kerosene and $1 \%$ of water. In this experiment, the influence of graduated cylinder diameter also was investigated. The graduated cylinder used in this experiment were diameter of $65.0 \mathrm{~mm}$ and diameter of $60.0 \mathrm{~mm}$. The 
analytical balance (minimum readout mass $0.1 \mathrm{mg}$ ) had a below-balance-weighing hook for hanging measurement. Using a hanging wire, which did not extend due to the weight of the weighing bar, the weighing bar was hung from the analytical balance. The room temperature was approximately $298 \mathrm{~K}$. After thoroughly stirring the suspension using an agitator, the weighing bar was set with the balance. The measuring data, which consist of time $t$ and the corresponding mass of the bar $\mathrm{G}_{\mathrm{B}}$, were recorded. The measuring time was 1 hours and the data were collected in 1-second interval. After the measurement, the DSD was estimated based on the above-described theory. The Coulter counter method (Counter LS 100) was used as comparison method to measure DSD, and the gas chromatography was used to determine the purity of kerosene.

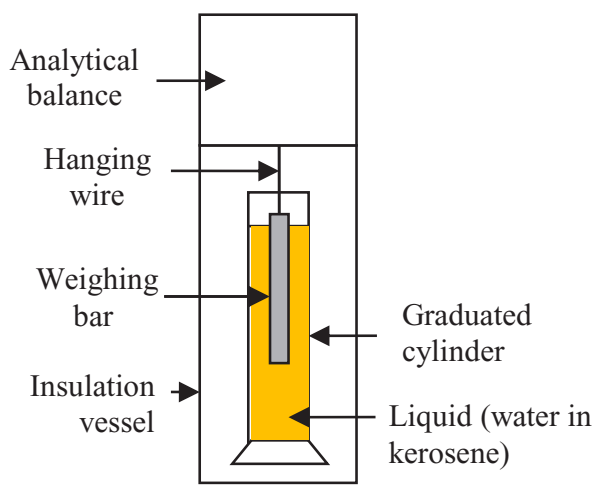

Fig. 1. Schematic diagram of experimental apparatus

\section{Results and Discussions}

Figure 2 showed the change with time in the apparent mass of weighing-bar $G_{\mathrm{B}}$ when ratio $99 \%$ : $1 \%$ of kerosene and water was used.

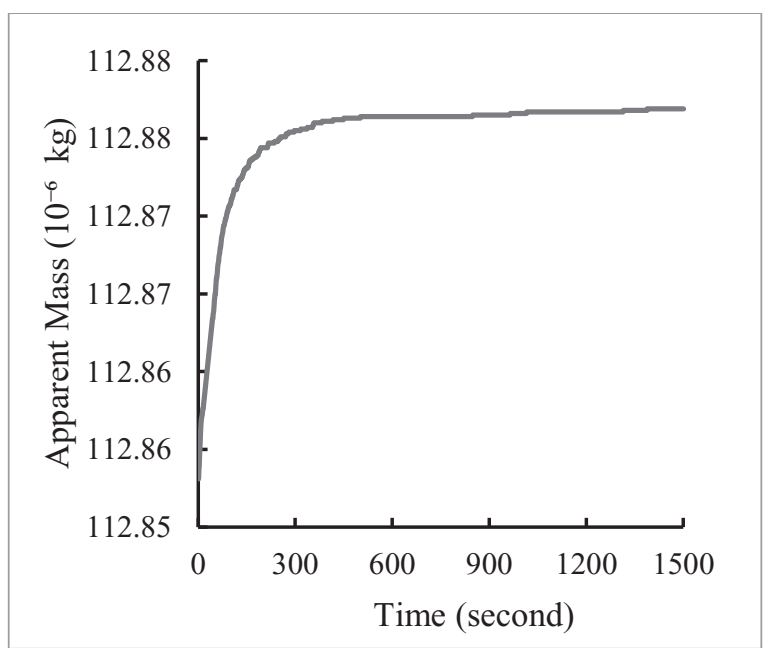

Fig. 2. Apparent mass of the weighing-bar as a function of time when ratio of kerosene and water was $99 \%: 1 \%$

The graduated cylinder diameter of $65 \mathrm{~mm}$ was used in this experiment. The figure showed that the apparent mass of the weighing-bar increased until all the water settled below the lower end of the weighing- bar, and then the apparent mass of the weighing-bar became constant. The change in the apparent mass was due to the change in the buoyant mass against the weighing-bar as well as water settling [14]. We could see at figure 2 that the weighing-bar started to become constant at 300 seconds of experiment when the larger droplets had settled, and constant at 1500 seconds when the middle and small droplets also settled below the weighing-bar. By using the gas chromatography, the concentrations of kerosene were about $89.3359 \%$ and $98.9741 \%$ at 300 seconds and 1500 seconds, respectively. Thus, figure 2 showed us that the separation time of water-kerosene mixture could be detected by using BWM.

Figure 3 showed the DSD of water in kerosene by BWM when ratio $99 \%: 1 \%$ of kerosene and water was used. These DSD were estimated by Stokes formula. The result obtained by using BWM gave the similar result to that measured by Coulter counter method. Hence, BWM could measure DSD of water in kerosene by using Stokes formula when ratio 99\% : 1\% of kerosene and water was used.

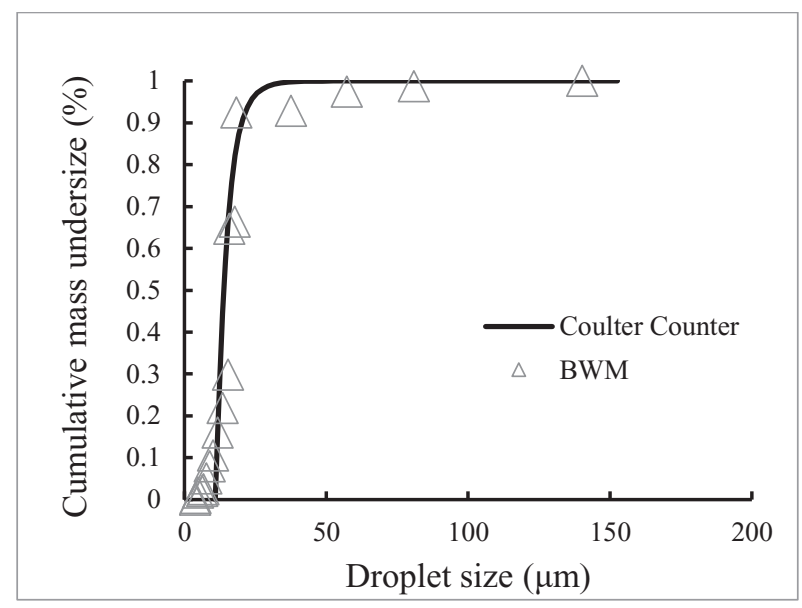

Fig. 3. The DSD of water in kerosene by using BWM when ratio of kerosene and water was $99 \%: 1 \%$

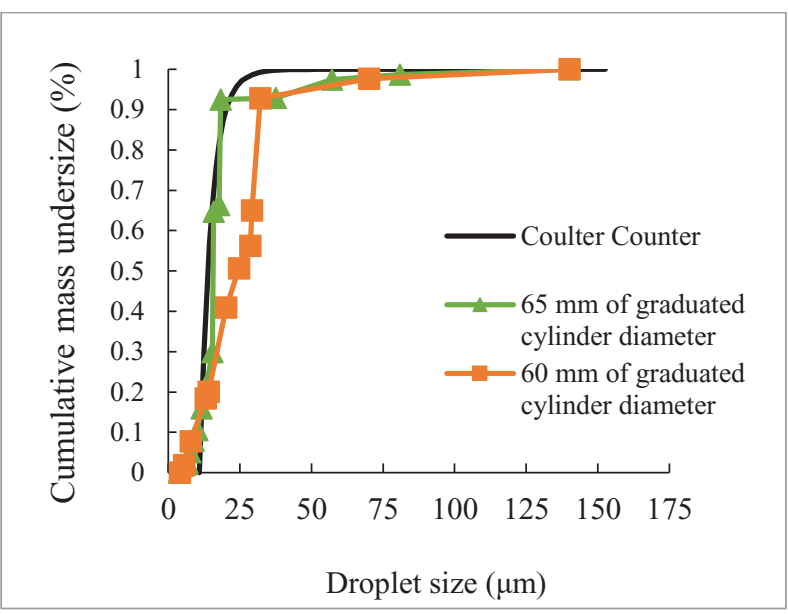

Fig. 4. Influence of graduated cylinder diameter in DSD determination of water in kerosene by using BWM when ratio of kerosene and water was $99 \%: 1 \%$

Figure 4 showed the influence of graduated cylinder diameter in DSD determination of water in 
kerosene by using BWM when ratio of kerosene and water was $99 \%: 1 \%$. The DSD obtained by using graduated cylinder diameter of $65.0 \mathrm{~mm}$ gave the closer result to that measured by a Coulter counter method than by using graduated cylinder diameter of $60.0 \mathrm{~mm}$. It was caused the wall effect and sectional area ratio of weighing bar and graduated cylinder influenced the migration velocity of droplet [15].

\section{Conclusions}

We have experimentally investigated the application of BWM to measure the DSD and optimal time of waterkerosene separation. From this study, the following results were obtained:

1. The BWM could determine the separation time of kerosene-water mixture when ratio $99 \%: 1 \%$ of kerosene and water was used.

2. The BWM could be used to measure the DSD of water in kerosene when ratio $99 \%: 1 \%$ of kerosene and water was used, and the precision of the DSD by using BWM is comparable to that obtained by a Coulter counter method.

3. The BWM used graduated cylinder diameter of $65.0 \mathrm{~mm}$ gave the closer result to that measured by Coulter counter method than using graduated cylinder diameter of $60.0 \mathrm{~mm}$.

The authors would like to thank Universitas Sumatera Utara for Research Grant, under TALENTA Fundamental Research Scheme 2017.

\section{References}

1. E. Obata, Y. Ohira, M. Ohta, Powder Technol. 196, 2 (2009)

2. T. Motoi, Y. Ohira, E. Obata, Powder Technol. 201, 3 (2010)
3. Y. Ohira, K. Furukawa, R. Tambun, M. Shimadzu, E. Obata, J. Sed. Soc. Jpn. 69, 1 (2010)

4. R. Tambun, T. Motoi, M. Shimadzu, Y. Ohira, E. Obata, Adv. Powder Technol. 22, 4 (2011)

5. R. Tambun, K. Furukawa, M. Hirayama, M. Shimadzu, S. Yamanaka, Y. Ohira, J. Chem. Eng. Jpn. 49, 2 (2016)

6. E. Obata, H. Watanabe, K. Mukaida, M. Akiyoshi, K. Ando, Kagaku Kougaku Ronbun. 12, 619-621 (1986)

7. N.G Stanly-Wood, E. Obata, H. Takahashi, K. Ando, Powder Technol. 60, 1 (1990)

8. E. Obata, K. Ando, Encyclopedia of Fluid Mechanics, Supplement 2, Gulf Publishing, Houston, (1993)

9. S. Odén, Soil Sci. 19, 1-35 (1925)

10. Y. Mao, L. Yong, H. Tao, W. Shimin, X. Yiqian, Wuhan Uni. J. of Nat. Sci. 3, 4 (1998)

11. J. A. Boxall, C.A. Koh, E.D. Sloan, A.K. Sum, D.T. Wu, Ind. Eng. Chem. Res 49, 3 (2010)

12. E.O. Fridjonsson, B.F. Graham, M. Akhfash, E.F. May, M.L. Johns, Energy Fuels 28, 3 (2014)

13. T. Allen, Particle size measurement, 4th edition, Chapman and Hall, London, (1990)

14. R. Tambun, M. Shimadzu, Y. Ohira E., Obata, J. Chem. Eng. Jpn. 45, 4 (2012)

15. R. Tambun, K. Nakano, M. Shimadzu, Y. Ohira, E. Obata, Adv. Powder Technol. 23, 6 (2012) 